\title{
Short Message Service (SMS) Health Awareness for Chronic Kidney Decease of Uncertain Etiology (CKDu) Patients in Sri Lanka
}

\author{
H. K. Salinda Premadasa ${ }^{1 *}$
}

${ }^{1}$ Sabaragamuwa University of Sri Lanka, SRI LANKA

*Corresponding Author: salinda@ccs.sab.ac.lk

Citation: Premadasa, H. K. S. (2021). Short Message Service (SMS) Health Awareness for Chronic Kidney Decease of Uncertain Etiology (CKDu) Patients in Sri Lanka. Journal of Information Systems Engineering and Management, 6(4), em0146. https://doi.org/10.21601/jisem/11396

\section{ARTICLE INFO}

Received: 9 Mar. 2021

Accepted: 26 Oct. 2021

\begin{abstract}
The fatal Chronic Kidney Disease (CKD) grounds for deaths and lowering life expectancy for a considerable amount of people in Sri Lanka. Continuing care and awareness of the disease helps to maintain reasonable control over the condition and prevent complications. The patient often receives such attention only at a medical clinic or doctor's visits. Hence, it is essential to identify alternatives for awareness of CKD patients. Here, we use SMS as a popular mobile technology tool to enhance the life expectancy of patients by improving their health. The study was carried out on a SMS group on 300 CKD patients who registered in CKD clinic, Nephrology and Transplantation Unit, Teaching Hospital Kandy for the analysis. The Independent $t$-test was applied to evaluate the impact of SMS awareness program. Then, the Paired $t$-test was conducted to evaluate the significance of results given by the independent $t$-test. The results revealed that the SMS awareness program positively impacted $(p$-value $<0.05)$ for increasing health condition of CKD patients. According to the Pearson Correlation, the result revealed that increasing health condition of CKD patients $(\rho>0.5$ and close to $1, p$-value $<0.05)$ has a strong relationship with the SMS awareness program. Further the analysis of variance results concluded that $(p-$ value $=0.008)$, there is a correlation between the number of referred SMSs and the increase of health condition. Thus, this would be better explained to improve the higher life expectancy of CKD patients.
\end{abstract}

Keywords: chronic disease, CKD patients, SMS awareness, quality of Life

\section{INTRODUCTION}

Despite concerted efforts from medical specialists, Sri Lankan public health sector has been plagued by some issues pertaining to the unabated spread of both communicable and non-communicable diseases. Some of these diseases has very high social significance due to their detrimental effects not only to the affected patients, but also for their families. Chronic Kidney Disease of Uncertain etiology (CKDu), easily topping the above mentioned list, has received a growing concern in medical circles ever since it was reported decades ago in Sri Lanka (Rajapakse, et al., 2016). Some studies estimate that the incidence of CKDu in Sri Lanka has been doubling every four to five years, so that currently greater than 150,000 people are affected by the disease and about $3 \%$ of them lose their lives annually (Wimalawansa, 2015; Epidemiology Unit of Ministry of Health, 2017). CKDu seems untamed, leaving several thousands of patients struggling for their lives and even more numbers at the first stages of the disease undetected. Knowledge on CKDu is largely scattered and ambiguous despite valiant efforts from researchers of different disciplines, to find its root-causes and remedies. Such efforts seemingly proceed at a sluggish rate, so as the preventive and curative measures of the disease (Rajapakse, et al., 2016; Redmon, et al., 2014)

$\mathrm{CKDu}$ is hitherto un-arrested and has been penetrated beyond the health boundaries. With that, the nature of CKDu management has become cumbersome and a foresight solution for the problem still at a distance. Consequently, in order to keep the affected people at the minimum favorable conditions, multi-facet approaches moreover to clinical management should be in place (Wijewickrama, et al., 2019). Such inline practices are diverse and direct or indirect in nature that comprises education, training, awareness, and other social aspects. Other than the functions of few organization for instance; Center for Education, Research and Training on Kidney Diseases (CERTKiD) of the University of Peradeniya, Sri Lanka, there is no formally established mechanism to CKDu patient care with such holistic approach. Consequently, when an event is ready to conduct it will benefit to limited number as they received the information through conventional manner such as Grama Niladhari (Village Officer), Public Health Inspector, Mid-wife, Social Service Officer. Such an event may be a screening clinic for clinically unattended people, clinic for already identified CKDu 
Table 1. SMSs sent by the research team

You should take very good care of your clinic day. If it is difficult to remember, let the person in charge know.

Use proper food recipes given by doctors or responsible people.

Exercising properly can help you to control your illness.

Drink clean water properly as directed by your doctor

Keep in mind that smoking can exacerbate your illness and even kill you.

Keep in mind that alcohol use can exacerbate your illness and can even kill you.

You need to be aware of your stage of illness properly. Then, by taking appropriate precautions, you can save your life.

Non-communicable diseases are on the rise. These include diabetes, high blood pressure, heart disease, kidney disease, cancer and respiratory disorders.

Non-communicable diseases often do not cause sudden illness, malaise, or death. Instead you have to live with these diseases for a long time. The most gratifying thing is that with the right treatment, one can spend the rest of one's life working with one's family and community with these diseases.

personal, awareness/training programme, social welfare event, event of safe agricultural practices, food and water related event etc.

Text messaging is simple and inexpensive intervention that can be automated and accessible to any mobile phone owner. Although the impact is small, but the potential benefits are worth the effort (Orr \& King, 2015). SMS notifications is a true mobile first technology adopted in the arena of mobile communication pedagogically, economically and technologically (Lominé \& Buckhingham, 2009). In 2017, the 7891.4 billion people regularly used SMSs in the world. Many of them use it almost every day and that number is still rising (Portio-Research, 2017). Mobile phone interventions for health are an emerging, rapidly evolving practice and have been used to improve delivery of health services in many countries of the world (Lee, et al., 2018). Also, the SMS can be a low cost solution to provide health education and communication, and increase adherence to treatment for people with chronic diseases (Sarabi, et al., 2016).

\section{RELATED WORKS}

The texting (SMSs) on mobile phones proves that they can provide advice and support in setting the lifestyle needed to prevent high-risk men from type 2 diabetes (Ramachandran, et al., 2013). SMS is an appropriate and promising tool for disease control interventions in developing countries. Accordingly, the SMS service seems to provide a great service for the prevention, monitoring, management and treatment compliance of communicable and non-communicable diseases (Déglise, et al., 2012). The awareness and familiarity of people with the use of mobile phones is essential for managing health and service delivery. In addition, people's socio-demographic factors, device perception, and health information also play a vital role for providing healthcare services (Pai \& Alathur, 2019). Moradi and his colleagues (2019) have shown the educational intervention of SMS for resulting in improve foot care knowledge, foot care practices and metabolic control in patients with diabetes type 2 . Also, the effective and feasible SMS intervention would improve the behavioral habits of patients with chronic diseases in remote and undeveloped areas (Wang et al., 2020). Further, the combination of SMS reminders can be used with home blood pressure monitoring more effectively for lowering the systolic blood pressure in hypertension patients (Maharani, Pratiwi \& Mustikaningtias, 2018). Not only that, Mehmood and his colleagues (Mehmood et al, 2021) have shown the effectiveness of the SMS reminders for psychotic patients and families who have a positive approach to illness.

The 30.78 millions of mobile phone subscriptions have been reported in Sri Lanka in the year of 2019 (O'Dea, 2021) However, in Sri Lanka, there is no adoption of mobile technology in the health services. Hence, this study proposes a SMS notification system for CKD patients' health awareness in Sri Lanka and to evaluate the effectiveness of such a system for communicating health information. The proposed SMS health awareness program equally transfer such event related messages to all at once with no time and no labour dependence. Consequently, an SMS received by at least one of the members of a family will act as a vehicle for the total community of the area. Further, at the time of the event, it provides easy identification who attend and or who do not as the recipient base is known. Moreover, more specific matters for example, update health alert, safe messages against timely social chaos created aligned to the issue can also be successfully managed through the proposed mechanism.

\section{MATERIALS AND METHODS}

A web integrated and open-source bulk SMS delivering system (SMS notification system) was developed and then adapted to CKD patients for it. This system was optimized to deliver intended messages to the target group. These messages were generated with direct involvement of relevant medical experts. Centre for Education, Research and Training on Kidney Disease (CERT Kid), university of Peradeniya, Ministry of Health, Precedential task force on CKDu and other relevant authorities and research bodies were consulted in generating the desired messages. The proposed SMS notification system was centrally handled by the research team for the initial development and optimization phase, directly linked to the medical authorities. Information to be delivered and to whom it should be delivered were strictly in control of the medical authorities. Table 1 shows the SMSs sent by the research team under the supervision of medical authorities.

As illustrated in Figure 1, the proposed system enables a technical officer to post messages containing medical information to patients which are received from the health officer. Once a technical officer logs in to the system, a message relevant to a particular medical information is created with utmost 160 characters. Thereafter, this message is inserted into a database where an SMS daemon checks the 


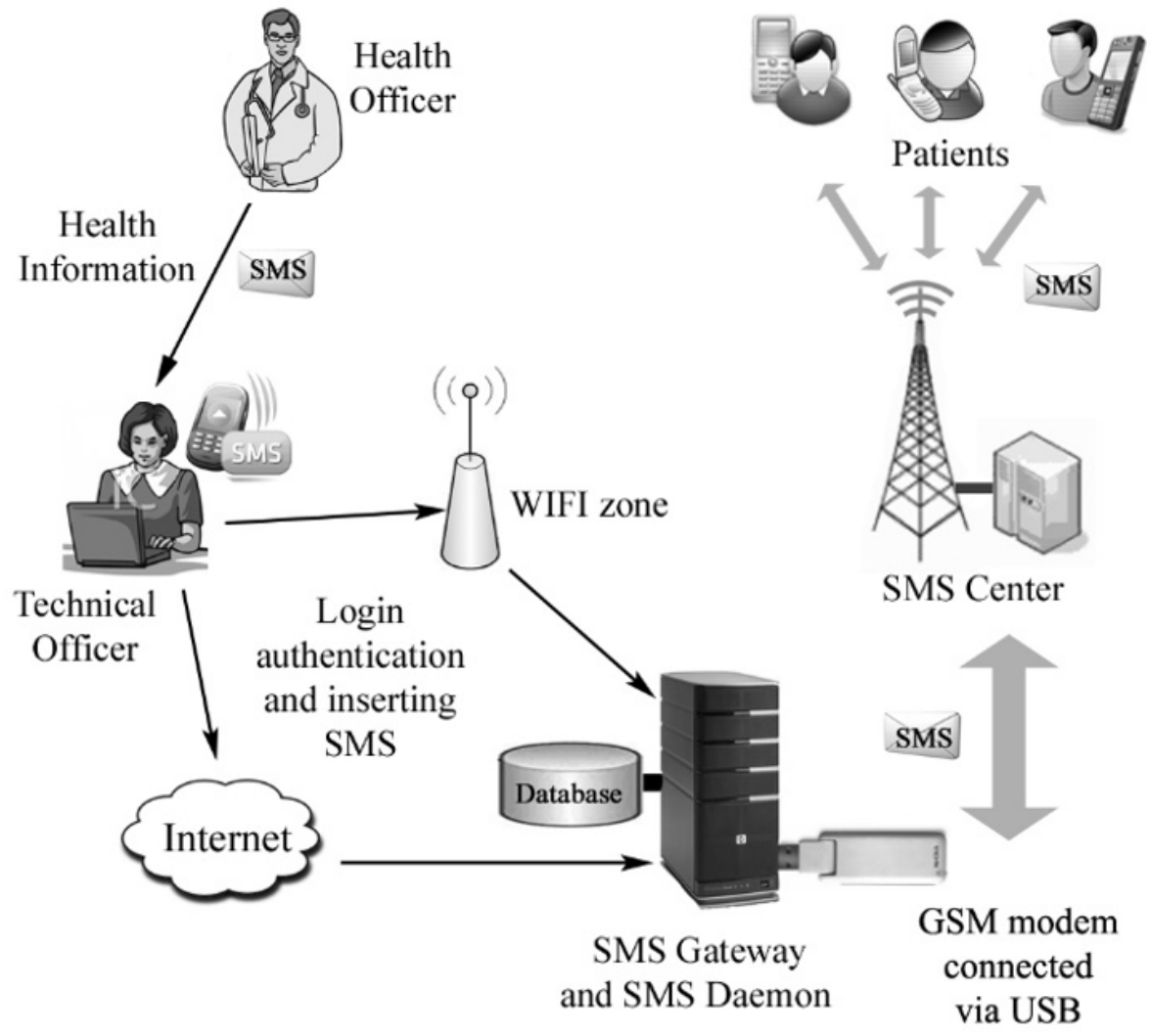

Figure 1. Architecture of the SMS awareness system

database periodically and sends out stored messages through an SMS gateway to a GSM modem. Using 'AT' commands, the modem in turn sends out SMS messages to all the recipients with access to that particular course unit through the SMSC. The SMS received by a patient contains the medical information such clinic dates, food behaviors, medical seminar dates etc. Subsequently, the patient is able to send a reply to the relevant SMS where the patient received. These reply messages are initially delivered to a database to be categorized depending on many factors by the system. Finally, an authorized user (technical officer or health officer) can explore all the messages posted relevant to the particular health information.

A quantitative analyzing method was undertaken to assess the efficiency of proposed SMS system that can be used to increase the health level of CKD patients. The research was undertaken between $1^{\text {st }}$ September 2018 and 31 ${ }^{\text {st }}$ March 2019 and carried out on the SMS group on CKD patients registered in the clinic, Nephrology and Transplantation Unit, Teaching Hospital Kandy. The 300 CKD patients were selected randomly for the analysis of that clinic and data were collected using following questionnaire.

Initially, the pre-survey questionnaire (Table 2: Q1, Q2, Q3...Q7) was given and collected data. Then, the awareness program through SMS was conducted within six months and 10 SMSs were sending to each of them. At the end of six months, data were collected again from all patients using the same questionnaire as the post-survey. Further, the $8^{\text {th }}$ question (Table 2: Q8) was included into the post-survey questionnaire by asking the amount of SMSs which the patient read among the 10 SMS. Further, data was coded according to the Likert scale as Answer - 1 (positive): +1 ; Answer -2 (Neutral): 0; and Answer -3 (Negative): -1 .

\section{ANALYSIS}

Preliminary analysis was obtained to get the idea about the difference (post-survey mean - pre-survey mean) comparing the pre and post-usage of the same group. The data set was tested using the Anderson Darling Normality test to analyze the distribution of data set. When the data set was normally distributed, the parametric test could be applied to the data set. Further, the Independent $t$-test was applied to evaluate the impact of SMS awareness program. A Paired $t$-test was conducted to evaluate the significance of results given by the independent $t$-test. Also, the Pearson correlation coefficient was calculated between difference (post and pre-usage) and number of referred SMSs. Finally, the number of referred SMSs by the patients (based on the Question-8) and the difference were shown in the regression model.

\section{RESULTS AND DISCUSSION}

The authenticity and responsibility of health information are essential when sending text messages to CKD patients. Therefore, in this study, health information was created to communicate for patients under the guidance of Nephrologist.

The 300 patients were participated in the pre-survey (Table 2: Questionnaire; Q1, Q2 .... Q7) and then encouraged to use the health information communicated through SMSs and instruct to follow up the information contained the SMSs. 
Table 2. Questionnaire

\begin{tabular}{|c|c|c|c|c|}
\hline No & Question & Answer - 1 & Answer - 2 & Answer -3 \\
\hline$\overline{\mathrm{Q}} 1$ & 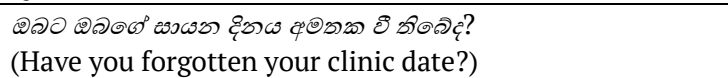 & 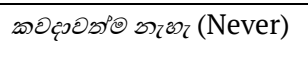 & 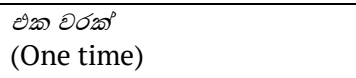 & ๑อง๑ふว่อిว (Often) \\
\hline Q2 & 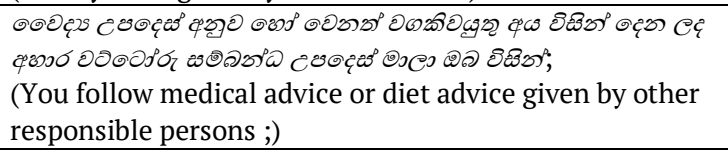 & 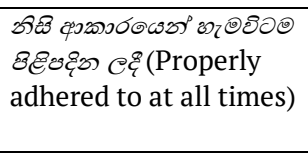 & 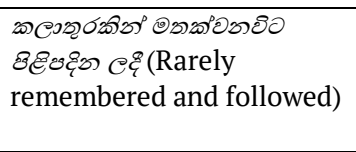 & 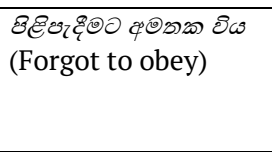 \\
\hline$\overline{\mathrm{Q} 3}$ & 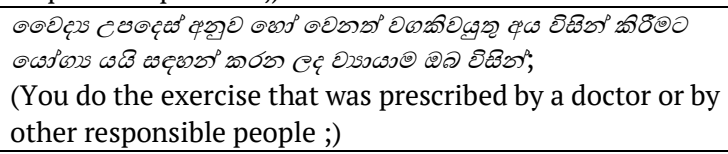 & 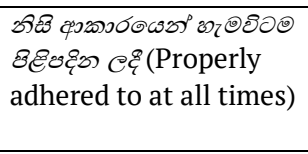 & 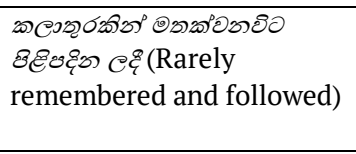 & 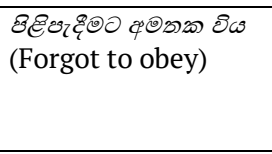 \\
\hline$\overline{\mathrm{Q} 4}$ & 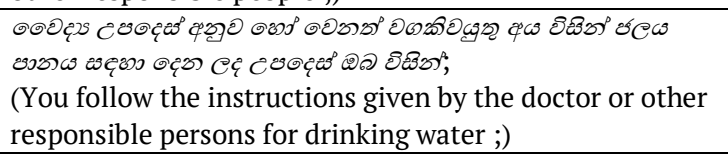 & 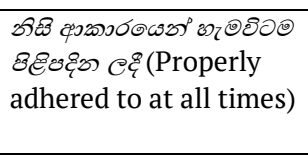 & 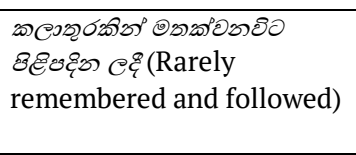 & 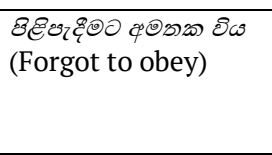 \\
\hline Q5 & 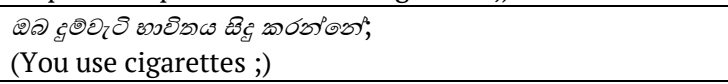 & 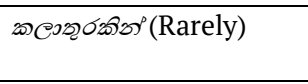 & 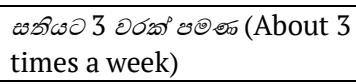 & 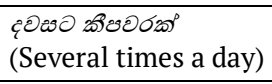 \\
\hline$\overline{\text { Q6 }}$ & 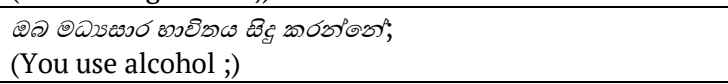 & 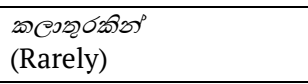 & 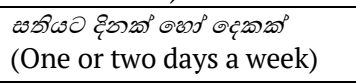 & $\begin{array}{l}\text { \&ुலßo } \\
\text { (Daily) }\end{array}$ \\
\hline Q7 & 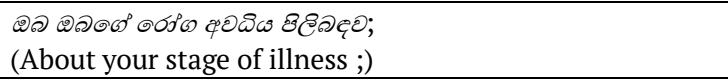 & 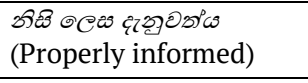 & 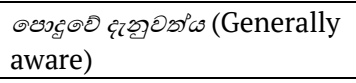 & 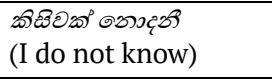 \\
\hline Q8 & 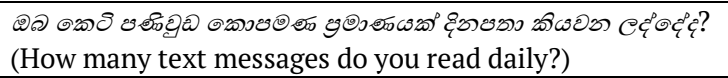 & & & \\
\hline
\end{tabular}

Table 3. Mean and their differences

\begin{tabular}{cccc}
\hline Question number & Pre-survey mean & Post-survey mean & Mean difference \\
\hline Q1 & -0.7267 & 0.7200 & 0.4467 \\
\hline Q2 & -0.2967 & 0.3033 & 0.4133 \\
\hline Q3 & -0.7400 & -0.3267 & 0.3733 \\
\hline Q4 & -0.5233 & -0.1500 & 0.1500 \\
\hline Q5 & 0.4833 & 0.6333 & 0.4600 \\
\hline Q6 & 0.1867 & 0.6467 & 0.9166 \\
\hline
\end{tabular}

Later, the post-survey questionnaire (Table 2: Questionnaire; Q1, Q2 ... Q8) was obtained. Mean values of each question was calculated for the data according to the post and pre survey separately. Mean differences between post and pre-survey were calculated (difference $=$ post-survey mean - pre-survey mean). Table 3 illustrates the means and differences made at the end of the survey.

The mean difference between post and pre survey under all questions (Q1, Q2, Q3, Q4, Q5, Q6, and Q7) are positive. This results revealed an impact on increasing the health of CKD patients with SMS health awareness program. Further, the analysis was carried out in advance with the Anderson Darling Normality test, and the results show that the $p$-value is less than 0.05 (Figure 2). This means the data set behaves in the normal distribution. Hence, the parametric tests such as paired $t$-test, correlation test and regression analysis could be applied for further evaluation.

The data set follows the normal distribution as well as data amount is exceeded 30 . Hence independent $t$ - test (parametric test) was used for advance analysis. Patient wise awareness amount was calculated using Likert code according to pre and post-survey first. Then increasing awareness amount of each person after conducting SMS health awareness program were calculated as below.

$$
\text { difference }=\text { post survey value }- \text { pre survey value }
$$

The paired $t$-test was applied to the difference to test the positive impact of the SMS awareness program. Also, the test was conducted under a 0.05 significant level defining the following hypothesis.

$$
H_{0}: \mu_{\text {diff }}=0 \quad \text { vs } \quad H_{0}: \mu_{\text {diff }}>0
$$

The results given in Figure 3 revealed that the SMS awareness program positively impacted ( $p$-value $<0.05, \mathrm{H}_{0}$ is rejected, Mean $>0$ ) for increasing health condition of CKD patients. Further, according to the Boxplot diagram shown in Figure 4, Box plot is laid after the 0 in the $\mathrm{X}$-axis. The mean value is near to the 5 of the $\mathrm{X}$-axis and greater than 0 . This would explain health condition of CKD patients is increased after conducting the SMS awareness program.

The number of referred SMSs by the patients were counted considering question $-8(\mathrm{Q} 8)$ in the post survey questionnaire. Then the Pearson correlation coefficient was calculated between the difference (post and pre-usage) and number of referred SMSs. Then, below rules were used to interpret the correlation coefficients.

Also, the hypothesis was defined below and tested with the $p$-value. If the $p$-value is less than 0.05 , the hypothesis is rejected at a 0.05 significant level.

$$
H_{0}: \rho=0 \quad \text { vs } \quad H_{1}: \rho \neq 0
$$

Figure 5 shows the output of the test.

The results given in Figure 5 revealed that increasing health condition of CKD patients $(\rho>0.5$ and close to $1, p$ value $<0.05$, and $\mathrm{H}_{0}$ rejected) has a strong relationship with the SMS awareness program. Due to the above-mentioned 


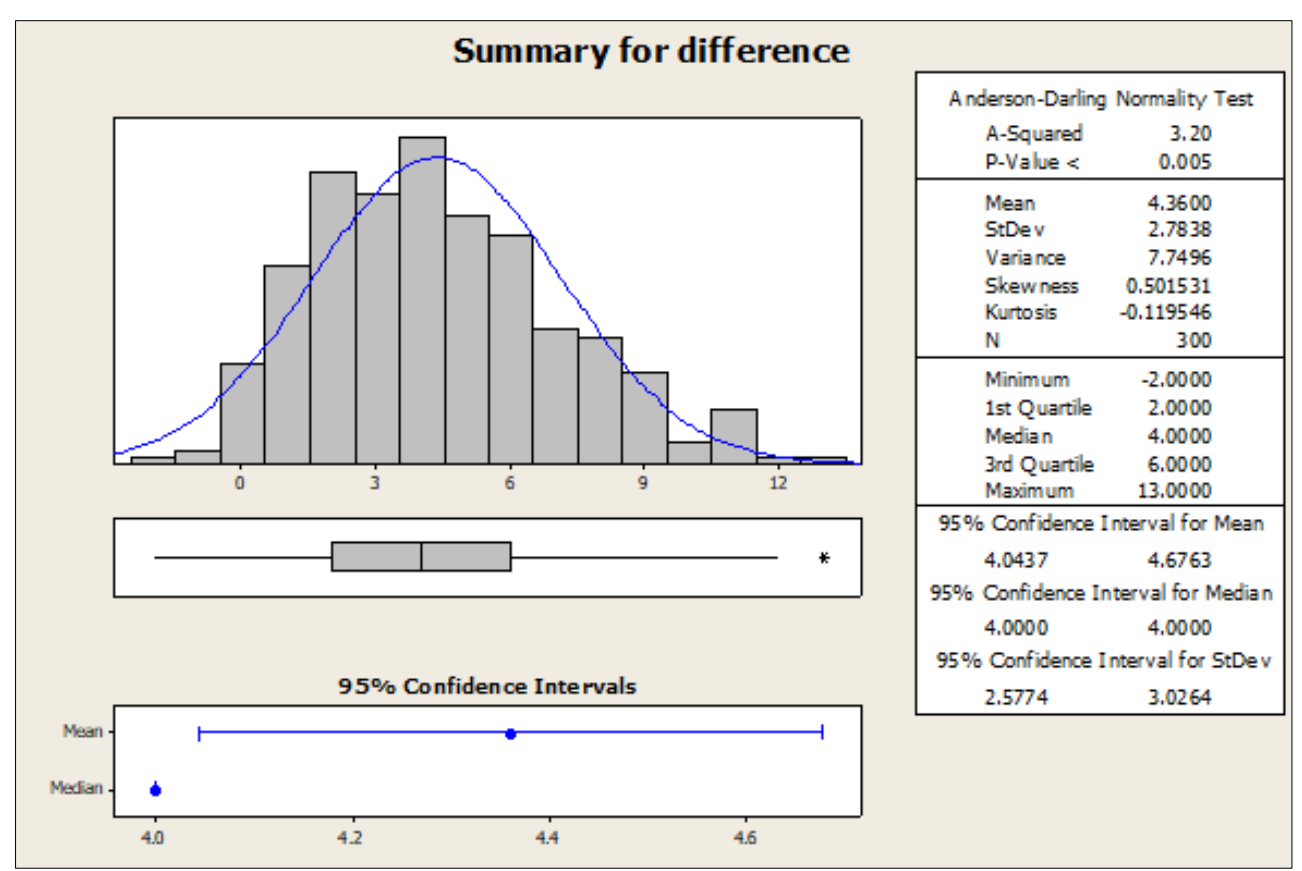

Figure 2. Results on Anderson Darling Normality test

\section{Paired T-Test and $\mathrm{Cl}$ : post, pre}

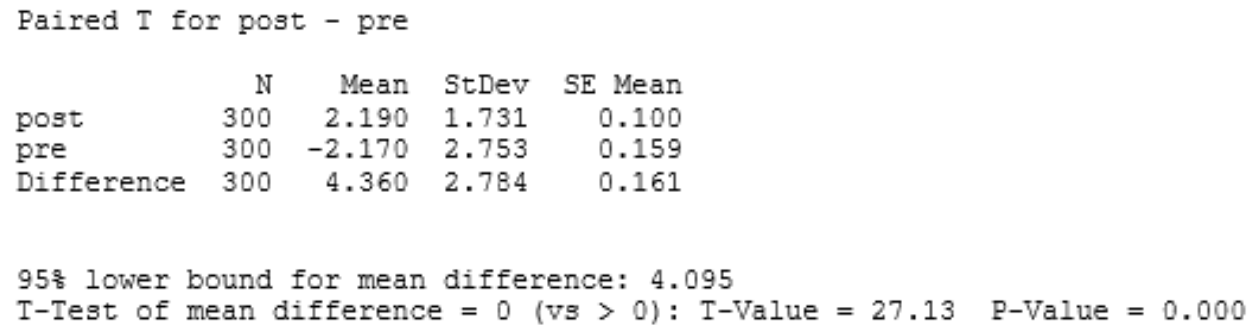

Figure 3. Paired $t$-test results

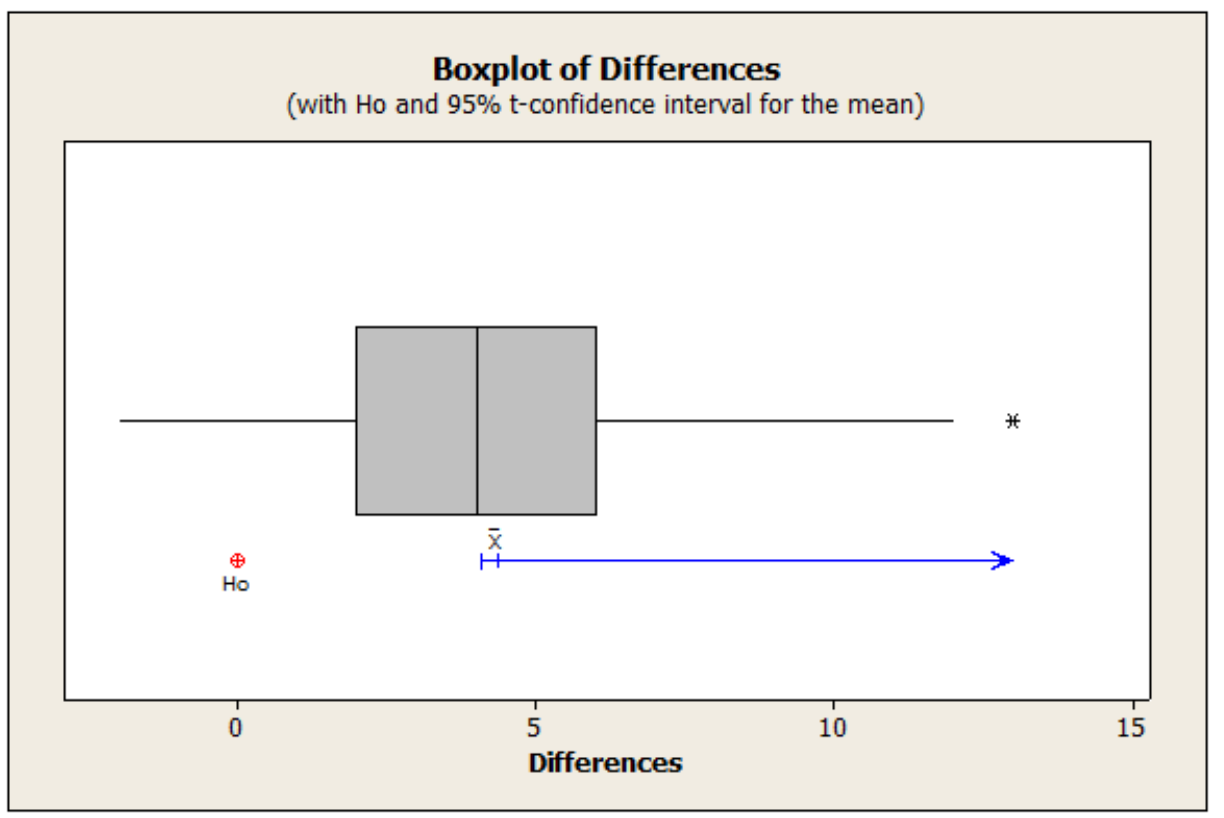

Figure 4. Boxplot of differences 
Table 4. Rules interpreted the correlation coefficients

\begin{tabular}{ccc}
\hline Correlation coefficient $-\boldsymbol{\rho}$ & Positive & Negative \\
\hline $0.0-0.3$ & No correlation & No correlation \\
\hline $0.3-0.5$ & Week positive correlation & Week negative correlation \\
\hline $0.5-1.0$ & Strong positive correlation & Strong negative correlation \\
\hline
\end{tabular}

\section{Correlations: difference, Q8 (10 SMS/day)}

Pearson correlation of difference and $Q 8$ (10 SMS/day) $=0.896$

P-Value $=0.008$

Figure 5. Correlation results

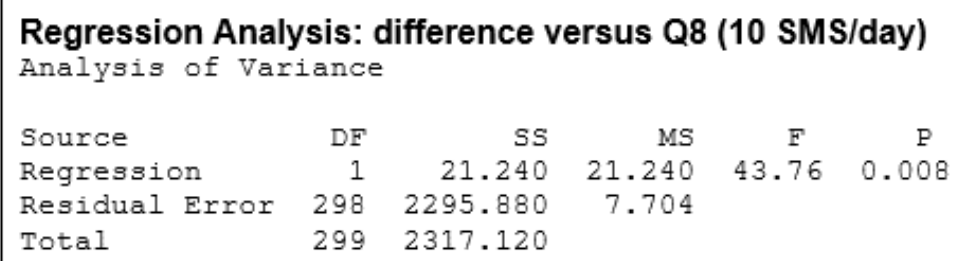

Figure 6. Analysis of variance

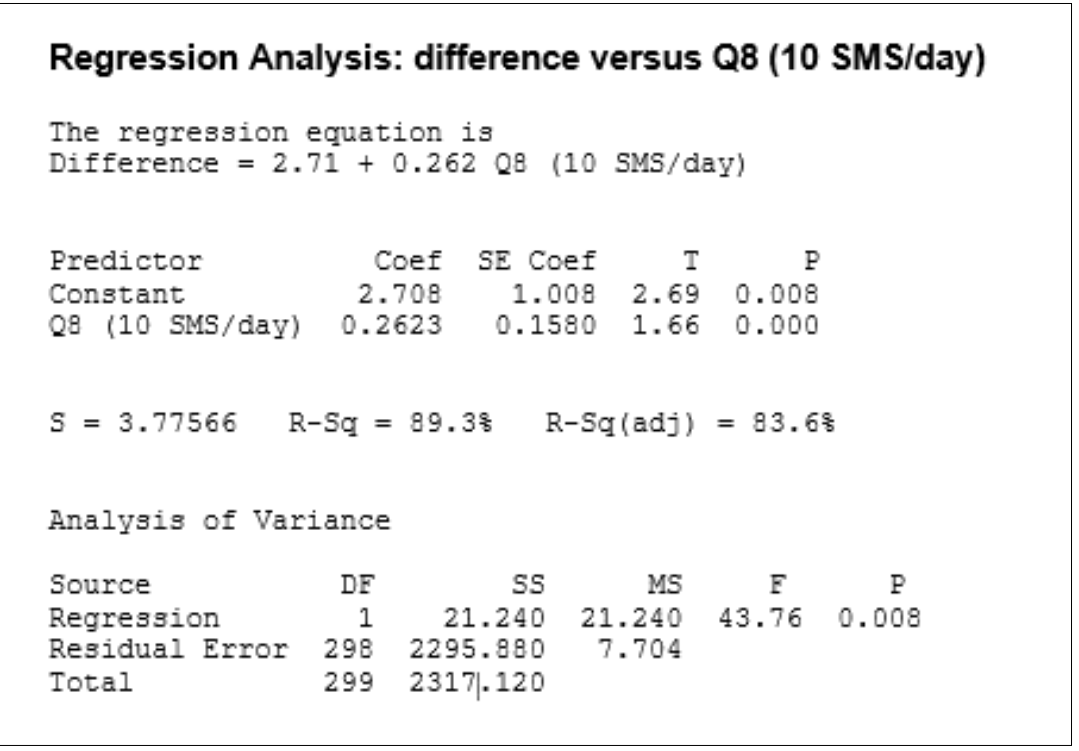

Figure 7. Regression analysis with correlation coefficients

correlation, the regression model was fitted by considering the number of referred SMSs as the independent variable while increase of health condition is the dependent variable. Analysis of variance output is used to test the overall goodness of fit of the model. This test measures how well the model describes the number of SMSs were referred, as shown in the following hypothesis.

$$
\begin{gathered}
H_{0}: b_{\text {const }}=b_{\text {health_awareness_amount }}=0 \\
\text { vs } \\
H_{1}: \text { at least one } b_{\text {value }} \text { is not equal to zero }
\end{gathered}
$$

Figure 6 shows the result of the test.
The results are given in Figure 6, further explain that $p$ value $=0.008(<0.05)$ in the analysis of variance, and therefore $\mathrm{H}_{0}$ is rejected, so there is a correlation between the number of referred SMSs to increase the health condition of CKD patients. Then the Likelihood Ratios test is used to evaluate the significance of individual coefficients in the model, and the relevant hypothesis was defined as follows.

$$
\begin{gathered}
H_{0}: b_{i}=0 \quad \text { vs } \quad H_{1}: b_{i} \neq 0 \\
\text { where } \mathrm{i}=0,1,2 \ldots
\end{gathered}
$$

The results in Figure 7 reveal that the individual $p$-values of constant $(p$-value $=0.008)$ and increase of health condition ( $p$-value $=0.000)$ were less than 0.05 , therefore $\mathrm{H}_{0}$ is rejected 
at a 0.05 significant level. Hence, it was concluded that the increase of health condition become significant in the given regression equation. Finally, the proposed regression equation can be defined as follows.

Increase of health condition (difference) $=2.71+0.2623$ Number of referred SMSs

\section{CONCLUSION}

The objective of the undertaken study is to examine how the number of referred SMSs impact significantly for increasing health condition of CKD patients. This research study is exclusive due to its outcomes conclude the use of SMS awareness program for getting proper knowledge about the disease, obtaining prevention mechanisms, adhering to health instructions, focusing on proper medical treatments. This would have an affirmative impact on higher life expectations for CKD patients. The prime benefit of this health awareness program is continuous education about the disease, prevention mechanisms, maintaining a healthy life, and expecting a long life of patients and their relatives who care for them. This research study is exceptional because it enables physicians to have an idea about patients' health condition based on the number of referred SMSs of the awareness program using the proposed equation. Further, patients can access more responsible health information continuously at their own homes and also able to send reply SMSs to this awareness program for further needs. Hence, this research study has significant practical implications for motivating CKD patients to keep up their life well-being. Future work is required to remind their clinic dates and automatically update the patients via SMSs under the supervision of a physician about the different stages of the disease.

Funding: This work was supported by the University Research Grant, Sabaragamuwa University of Sri Lanka under the Grant No. SUSL-RG-2017-02.

Declaration of interest: The author declares no competing interests.

Ethics approval and consent to participate: Not applicable.

Availability of data and materials: All data generated or analyzed during this study are available for sharing when appropriate request is directed to the author.

\section{REFERENCES}

Déglise, C., Suggs, L. S. and Odermatt, P. (2012). SMS for disease control in developing countries: A systematic review of mobile health applications. Journal of Telemedicine and Telecare, 18(5), 273-281. https://doi.org/10.1258/jtt.2012.110810

Epidemiology Unit of Ministry of Health. (2017). Prevalence and risk factors for $\mathrm{CKDu}$ in the district of Anuradhapura. Colombo: National Science Foundation of Sri Lanka.
Lee, J.-A., Choi, M., Lee, S. A. and Jiang, N. (2018). Effective behavioral intervention strategies using mobile health applications for chronic disease management: A systematic review. BMC Medical Informatics and Decision Making, 18(1), 12. https://doi.org/10.1186/s12911-0180591-0

Lominé, L. L. and Buckhingham, C. (2009). M-learning: texting (SMS) as a teaching \& learning tool in higher arts education (pp. 1-6).

Maharani, L., Pratiwi, H. and Mustikaningtias, I. (2018). The impact of Short Message Service (SMS) reminder and home monitoring on blood pressure control in hypertension patients: A case study of two primary health care facilities in Banyumas Regency. Muhammadiyah International Conference on Health and Pharmaceutical Development, 1(1), 5-10. https://doi.org/10.5220/0008238400050010

Mehmood, N., Talib, U., Rehman, R. U. and Naeem, F. (2021). The treatment approach of patients and their families and impact on SMS reminder toward OPD follow up of psychotic patients. International Journal of Endorsing Health Science Research, 9(1), 83-87. https://doi.org/10.29052/IJEHSR.v9.i1.2021.83-87

Moradi, A., Alavi, S. M., Salimi, M., Nouhjah, S. and Shahvali, E. A. (2019). The effect of short message service (SMS) on knowledge and preventive behaviors of diabetic foot ulcer in patients with diabetes type 2. Diabetes \& Metabolic Syndrome: Clinical Research \& Reviews, 13(2), 1255-1260. https://doi.org/10.1016/j.dsx.2019.01.051

O'Dea, S. (2021). Number of mobile cellular subscriptions in Sri Lanka from 2000 to 2019. New York, USA: Statistica Corporate Solutions.

Orr, J. A. and King, R. J. (2015). Mobile phone SMS messages can enhance healthy behaviour: a meta-analysis of randomised controlled trials. Health Psychology Review, 9(4), 397-416. https://doi.org/10.1080/17437199.2015. 1022847

Pai, R. R. and Alathur, S. (2019). Assessing awareness and use of mobile phone technology for health and wellness: Insights from India. Health Policy and Technology, 8(3), pp. 221-227. https://doi.org/10.1016/j.hlpt.2019.05.011

Portio-Research. (2017). Worldwide A2P SMS markets. Chippenham: Portio Research Limited.

Rajapakse, S., Shivanthan, M. C. and Selvarajah, M. (2016). Chronic kidney disease of unknown etiology in Sri Lanka. International Journal of Occupational and Environmental Health, 22(3), 259-264. https://doi.org/10.1080/10773525. 2016.1203097

Ramachandran, A., Chamukuttan, S., Ram, J., Selvam, S., et al. (2013). Effectiveness of mobile phone messaging in prevention of type 2 diabetes by lifestyle modification in men in India: A prospective, parallel-group, randomised controlled trial. The Lancet Diabetes \& Endocrinology, 1(3), 191-198. https://doi.org/10.1016/S2213-8587(13)70067-6 
Redmon, J. H., Elledge, M. F., Womack, D. S., Wickremashinghe, R., et al. (2014). Additional perspectives on chronic kidney disease of unknown aetiology (CKDu) in Sri Lanka-lessons learned from the WHO CKDu population prevalence study. BMC Nephrology, 15(1), 1-10. https://doi.org/10.1186/1471-2369-15-125

Sarabi, R. E., Sadoughi, F., Orak, R. J. and Bahaadinbeigy, K. (2016). The effectiveness of mobile phone text messaging in improving medication adherence for patients with chronic diseases: A systematic review. Iranian Red Crescent Medical Journal, 18(5), e25183. https://doi.org/10.5812/ ircmj. 25183
Wang, X., Liu, D., Du, M., Hao, R., Zheng, H. and Yan, C. (2020). The role of text messaging intervention in Inner Mongolia among patients with type 2 diabetes mellitus: a randomized controlled trial. BMC Medical Informatics and Decision Making, 20(1), 1-11. https://doi.org/10.1186/ s12911-020-01129-7

Wijewickrama, E. S., Gunawardena, N., Jayasinghe, S. and Herath, C. (2019). CKD of unknown etiology (CKDu) in Sri Lanka: a multilevel clinical case definition for surveillance and epidemiological studies. Kidney International Reports, 4(6), 781-785. https://doi.org/10.1016/j.ekir.2019.03.020

Wimalawansa, S. J. (2015). Agrochemicals and chronic kidney disease of multifactorial origin: Environmentally induced occupational exposure disease. International Journal of Nephrology and Kidney Failure, 1(2), 1-9. https://doi.org/10.16966/2380-5498.111 